Dunedin, who are unable to discover anything out of the ordinary. The chief asks for silence and a hush falls on the scene. The assembled natives break into loud cries, and along a track in the jungle-like growth can be seen a party of ten Fijians fantastically dressed.

"Without hesitation or haste, they step on to the stones and walk round the pit, taking some ten to fifteen seconds to complete the circuit. They step off quickly, and in a moment great masses of green leaves are thrown on to the centre. The fire-walkers rush back and press down the leaves with their feet and hands. The steam rising from the leaves envelops them in a cloud. Baskets of native food are passed in, and more green leaves are heaped over until a mound is made."

Dr. Fulton states that the man Dr. Smith and he examined before the fire-walking was of fine physique, with a pulse a little over 90 and the hands and feet cooler than the rest of the body. The feet were perfectly clean and odourless, and no preparation could be detected on them. The soles were yellowish-white, perfectly smooth and pliable, and like soft kid. The man wore a sulu (petticoat) of dry hibiscus bark and canna leaves, with small anklets of dry bracken. Each man as he walked kept his eyes on the stones. One man was examined afterwards; his pulse was about $\mathrm{I} 20$; the soles of the feet seemed cool, if not cold, but on running the hand up the leg, a most pronounced difference in temperature was observable ; on the calf, it was like that of a man in a high fever. None of his vegetable clothing was scorched, not even the dry bracken anklets, and the short, black, crisp hairs on the legs were not singed. Dr. Fulton went to the edge of the pit immediately after the ceremony and stirred up some of the stones with his foot. He stood for a second on one or two and found that they did not brown his boots, though evidently they were too hot to handle. He asked a native to get him one of the stones, and the man coolly walked up and began to move about the heated stones with his bare feet. This was not one of the "fire-walking" men, but one of those who had come from Suva. He raked out a piece of stone from the heap, but it was too hot to hold in the hand.

The explanation Dr. Fulton offers is as follows. The arrangements for heating were peculiar; if what was required was merely a surface of red-hot stones to walk upon, it would be easier to lay flat stones in the pit and to maintain a huge fire on them. The stones took fortyeight hours to get to their "proper" condition, and the subsequent cooking of the food took two days instead of an hour or so. The stones also were found to cool very slowly. The same stones are never used twice. They are gradually heated until split by the expansion of the contained water, and are then carefully arranged fractured side upwards. The stone that was examined was an augite-andesite of ordinary type. Prof. Park, of the Otago School of Mines, found that, taking the thermal conductivity of copper as equal to Iono, that of andesite is 6.67 , that is, it is a very feeble conductor of heat. In testing the radiation, iron being the standard at roo, andesite is 48 . Thus the fractured, or inside, surface of the stone, owing to its slow conductivity, does not receive nearly the amount of heat one would expect, and, owing to the slow radiation of heat, the foot is not burnt when coming into contact with the stone for a. second or less; as a matter of fact, the sole of the foot was at no time in contact with a hot stone for more than half a second. The foot is naturally cold or artificially cooled; it is a well-known fact that one can bear with cold feet for a long time (up to a minute in some instances) heat from a fire which would be insupportable for five seconds at ordinary foot temperature.

A good deal has been written at various times on walking on heated stones or glowing embers. It will be in the knowledge of our readers that there was published in NATURE of August 22, 1901, an article on NO. 1728 , voL. 67$]$
Tahitian fire-walking, by Prof. S. P. Langley, in which a somewhat similar explanation was given. It is satisfactory to find that these investigations by scientific men agree, on the whole, with one another in principle, and that a rational explanation is forthcoming for a sensational performance which unskilled white observers usually regard as mysterious or even as miraculous. The walking on glowing embers, which is well known in parts of India, as recently described in the Bulletin of the Madras Government . Iuseum (vol. iv. 190I, p. 55), probably has another solution. The fire-walking ceremonies in India, Japan and elsewhere require to be carefully studied by trained observers.

A. C. $\mathrm{H}$

\section{THE PRESENT STATE OF WIRELESS TELEGRAPHY.}

$\mathrm{I}^{\mathrm{T}}$ is now eighteen months since we last attempted in these columns to take a general survey of the development of wireless telegraphy. In the history of a science which has enlisted the services of so many skilled experimentalists, each of whom has made rapid progress along his own lines, eighteen months is a comparatively long period ; as a result, we are compelled to-day to regard the subject from a very different point of view. At that time, there were practically only two systems-Mr. Marconi's and Prof. Slaby's - which had advanced to such a degree of perfection that they deserved special consideration. To-day, it would hardly be too much to say that in every civilised nation there are one or more inventors with a carefully worked-out and tested system ready for general use. Particulars of these different systems have been published from time to time and have been duly referred to in NATURE; unfortunately, the information published is not, as a rule, of the kind that one most desires to obtain; too often it is obviously "inspired," and consists for the most part of insufficiently supported claims to successful syntonisation, or to record making in the way of long-distance transmission or rapid signalling, information which is very acceptable to the daily papers, which forget one day what they have published the day before, but of little use to those who are seriously inter. ested in the subject.

So far as can be judged, the various systems differ chiefly in matters of detail, the design of circuits and the special construction and arrangement of apparatus ; improvements depending on the introduction of a principle fundamentally new are few and far between. We do not wish to underrate the value of these detailed improvements ; they are, as we well know, often the talismans converting failure into success, but their interest is mainly for the specialist It is not our intention, therefore, to enter into a detailed examination of the different systems ; to do so would only involve us in a mass of technicalities from which the reader would probably "come out by that same door where in he went." Those who wish for this information must be referred to the technical Press or to the files in the Patent Office, where they will probably find, as, for example, in the two hundred odd claims in Mr. Fessenden's patents, all the particulars they desire. We propose rather to treat the subject on a broader basis, and to endeavour to form an estimate of how far wireless telegraphy in its present state has fulfilled the expectations that have been raised in the past or justifies hopes that may now be entertained for a future of wide utility.

The first question that one feels inclined to ask is, At what end are all these inventors aiming? Is it to devise a system of wireless telegraphy to compete with the ordinary telegraphic methods, or is it for what seems to us the more useful purpose of creating a means of communication where none now exists, especially between ship and ship and ship and shore? It would seem that in some instances, as, 
for example, that of the Marconi Company, the former purpose is almost as much in view as the latter. In the former case, there can be no question but that absolute syntonisation is necessary ; in the latter, it is less important and even in some respects undesirable, but, on the other hand, it is essential that the different systems should work together so that any ship should be able to signal to any station. It would be a great misfortune if this principle is lost sight of in the rivalry between competing methods and if we thereby lose what seems to be in reality the greatest benefit wireless telegraphy can confer, the increase of the safety and convenience of travelling by sea. This is, we think, the most urgent problem that wireless telegraphy presents to-day, and we trust that it will find a really satisfactory solution at the coming Berlin Conference.

The attempts which have been made at syntonisation are, indeed, far from encouraging. It is true that almost every inventor claims that he has solved the problem, but all the experiments that have been quoted are open to criticism. It is important to recognise what a successful solution really means; it is not sufficient to demonstrate, as has been done many times, that two messages can be transmitted or received at the same time by the same installation without interference ; that, in short, duplexing is possible : this is a great step, no doubt, but to solve the problem it is necessary that the tuned transmitter shall affect no other receivers than those syntonised with it, and that the tuned receiver shall respond only to the proper waves ; this, it will be seen, is a requirement much harder to satisfy. As an example, showing how far existing practice is from satisfying these conditions, we may quote the case of the recent long-distance work done by the Marconi Company. Mr. Marconi, it will be remembered, has several times claimed to have solved the problem of syntonisation, and, confident of having done so, issued a challenge last February to Sir W. Preece or Sir O. Lodge to intercept any of his messages, offering to put a station, in the neighbourhood of his Poldhu station, at their service. This challenge has been answered in a conclusive manner during the past month by Mr. Nevil Maskelyne, who showed that the installation which be was working at Portcurnow had been receiving the messages sent to the Carlo Alberto on her recent cruise from England to Italy (see the Electrician, vol. 1., pp. 22 and 105). It is clear, therefore, that, with no special preparation on either side, it is possible to tap the signals that are being sent by the Marconi Company over long distances, and in face of this the claims to a real solution of the syntonisation problem fall to the ground. We doubt whether any other system would stand the same test.

But if on this side the outlook is somewhat dispiriting, in other directions matters are more encouraging. This year has witnessed the remarkable achievements by the Marconi Company in long-distance work. It has been shown that it is possible to signal across the Atlantic, a distance of more than 2000 miles over water; and in the cruise of the Carlo Alberto signals were transmitted a distance of 750 miles over land and water. To cover these great distances, the power used at the transmitting station has to be correspondingly great ; in consequence, the signalling was only from Poldhu to the ship and not in the reverse direction. The importance of these experiments, however, lies rather in the conclusive demonstration of the fact that it is only a question of providing sufficient power to signal over any distance, however great, and therefore no fears need be entertained of the utility of the wireless telegraph being limited by considerations of distance. No other experimenter has attained such success in long-distance work as Mr. Marconi, but no other experimenter has used such large power for transmission. Unfortunately, sufficient particulars are not available to enable a comparison to be made between the distances attained with different systems using the same amount of power; this is a point on which the No. $\{728$, VOL. 67$]$ publication of trustworthy data would be of the highest value. An interesting phenomenon brought out by $\mathrm{Mr}$. Marconi's long-distance work is the effect produced by daylight on transmission. It is found that the signals carry much further during the night (i.e. night at the transmitting station), the result being due, it is suggested to the discharging effect of sunlight on the aërial wire (see NATURE, vol. lxvi. p. 385 ).

With reference to long-distance work, the interesting experiments of $M$. Guarini with an automatic repeater may be quoted. This inventor designed an apparatus which should pick up a message received from one station, $A$, and pass it on to a second station, B, which was out of the range of the signals transmitted direct from $A$. The principle of this apparatus will be understood from the accompanying diagram (Fig. I), in which, for the sake of clearness, only the essential circuits are shown. The aërial wire $A$ at the repeating station is connected through the contact $I$ of the relay $R_{1}$ and through the primary of a transformer $\mathrm{T}$ to earth ; it is also connected through the spark gap $\mathrm{S}$ to earth. The coherer is connected in series with the secondary of $\mathrm{T}$ and a condenser. When a signal is received, the resistance of the coherer is broken down, and the battery $B_{1}$ sends a current through it and the relay $R_{2}$, thus closing at the contact 3 the

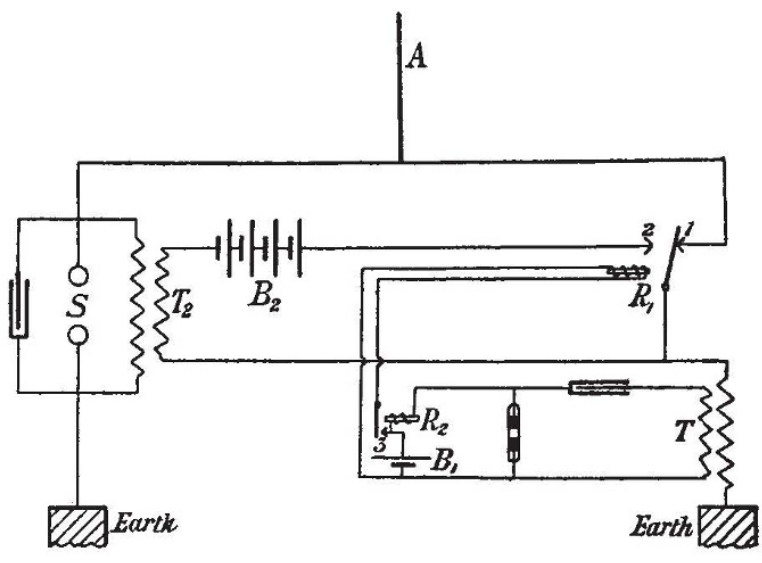

FIG. 1.-Diagram of Circuits in Guarini's Repeater.

circuit of the relay $R_{1}$. The contact arm of $R_{1}$ swings over to 2, thus disconnecting the aërial from the receiving circuit and closing the primary of the induction coil $\mathrm{T}_{2}$, thereby causing a spark to pass across the gap, which means that the signal is sent out again from the aërial $\mathrm{A}$. The coherer being tapped back, the various circuits are opened, and the arm of $\mathrm{R}_{1}$ returns to its original position and so is ready to receive the next signal. Experiments were carried out between Antwerp and Brussels ( $42 \mathrm{~km}$.), the repeating station being at Malines, about half-way between the two; the results were promising, though the repeater did not prove absolutely trustworthy.

We may now turn from the consideration of the results achieved to the apparatus that has been used. In the transmitting apparatius, attention has been chiefly devoted to devising means of generating oscillations of definite wave-length. None of these call for special comment. In some cases, for obtaining the spark, alternating-current generators have been employed in connection with stepup transformers instead of induction coils. This is the case in the de Forest system, which, it may be remarked, claims the record for speed of forty-eight words per minute the alternator generates, at 500 volts, 60 cycles, and this is stepped up to 25,000 volts for sparking; the signals are formed by interrupting the primary circuit of the transformer by means of a specially designed key. The diffi. culty of breaking a large current in this way is consider- 
able, and has obviously proved a stumbling-block to the Marconi Company, as it forms the subject-matter of two or three patents taken out by Prof. Fleming and the Company. Some of the methods described therein are exceedingly ingenious, but, unfortunately, space does not allow us to describe them here, especially as their bearing on wireless telegraphy is only indirect.

With the exception of the magnetic detector devised by Mr. Marconi and tested during the cruise of the Carlo Alberto, practically all the different systems make use of the coherer principle for receiving. The actual type of coherer used differs considerably in the several cases. For long-distance work, it has generally been found most suitable to use a coherer which requires no tapping back, but spontaneously returns to its normal condition, this being connected in parallel with a telephone. One of the chief advantages of this arrangement lies in the fact that the energy required to give audible signals in the telephone is much less than that needed to work a relay. There are several different coherers working on this principle-the principle really of the microphone ; in the system devised by M. Popoff, carbon granules form the loose contacts, the resistance, which is normally high, being broken down by the received waves and the coherer then restoring itself to its original condition; the change

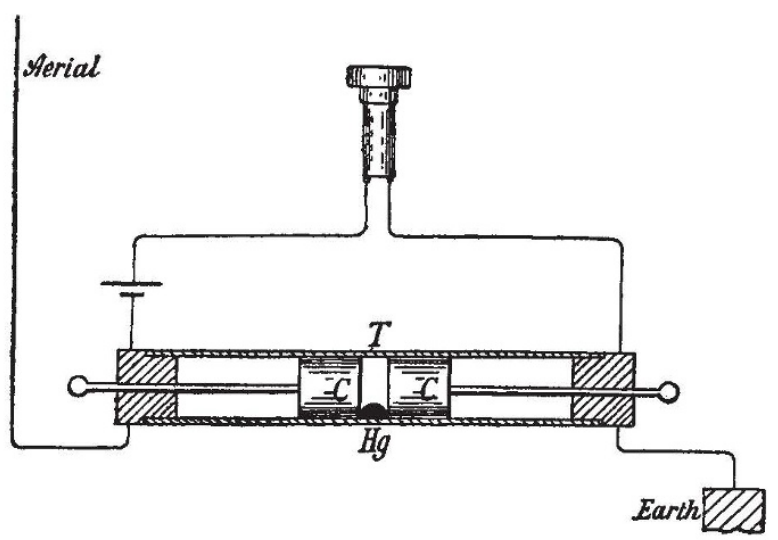

Fig. 2.-Castelli Coherer and Connections.

in the current through the coherer causes a click in the telephone. In the de Forest system, an electrolytic "anticoherer" is used; this has a paste, composed of a viscous material, loose conducting particles and an electrolyte, between suitable electrodes. In the normal condition, the conducting particles bridge the gap and give the receiver a low resistance; electrolysis is set up by the received oscillations and the consequent polarisation greatly increases the resistance. Of the coherers of this type, the greatest interest attaches to the Castelli coherer. This, invented by a semaphorist in the Italian navy, was used by Mr. Marconi in his first Transatlantic experiments. Its construction is shown in Fig. 2. Two iron or carbon electrodes, C C, fit into the tube $\mathrm{T}$ and are connected by a single drop of mercury $\mathrm{H} g$. The connections shown are, of course, the same in the case of the two other coherers just described. When elertrical oscillations reach the tube, the mercury coheres to the electrodes, but returns at once to its normal condition when the stimulus ceases. The magnetic detector to which we have made reference above was described by Mr. Marconi in a paper read before the Royal Society last Jine. Fig. 3 shows the principle of its construction. It consists of a core of thin iron wires, I, over which are wound two coils of fine copper wire, $c_{1}$ and $c_{2}$. The outer core, $\mathrm{C}_{1}$, is connected to a telephone receiver and the inner, $C_{2}$ to the aerrial and earth or to the secondary of a trans former the primary of which is connected to the aërial NO. I 728 , VOL. 67 ] and earth. The iron core is magnetised by a permanent magnet, $M$, at one end, which is rotated by clockwork so as to produce a continual slow change in the magnetis ation, which, however, owing to the hysteresis, lags behind the magnetising force. When oscillatory currents pass through the inner coil, there is a sudden decrease in the hysteresis, due apparently to the molecules being released from restraint; a corresponding sudden variation in the magnetisation of the iron results, and this induces a current in the outer winding connected to the telephone.

Such, in brief, are the more important advances that have been made in the practice of wireless telegraphy during the past year. In addition, much work has been done on the purely scientific side of the subject, the action of the coherer in particular having. been submitted to somewhat rigorous examination, work which has already produced results which may prove bot of great physical and great practical value. It may fairly be said that we know now, with a considerable degree of certainty, some of the more useful services which wireless telegraphy may be relied upon to perform. Already its commercial application is considerable ; many ships, in the navies of this and other countries and in the merchant services, are equipped with wireless telegraphic apparatus which has, we believe, fully justified its instal-

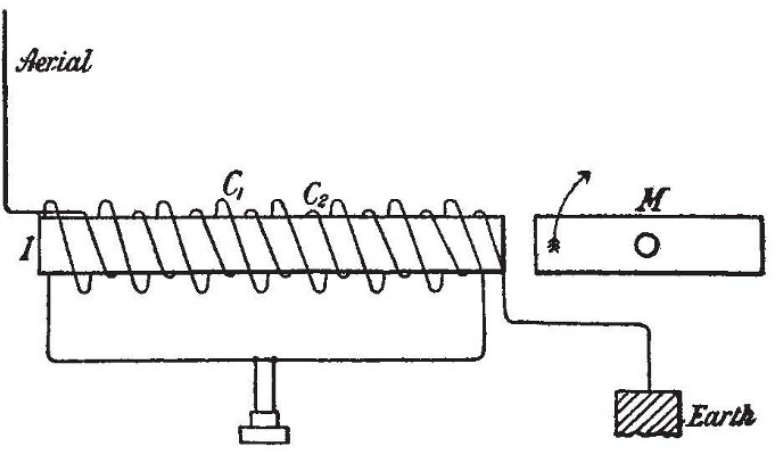

FIG. 3.-Diagram of Marconi's Detector.

lation. It is in this direction that we look with the most confidence for a steady increase in its application, and we would rather hear of a few more ships being thus equipped than of another " $\mathrm{S}$ " being transmitted across the Atlantic. MAURICE SOLOMON.

\section{NOTES.}

THE Paris correspondent of the Times announces the death of M. Dehérain, professor of vegetable physiology in the Museum of Natural History, and of M. Hautefeuille, mineralogist at the Faculty of Sciences. Both were members of the Paris Academy of Sciences. The death is also announced of M. Alexandre Bertrand, one of the original founders of the fine museum of St. Germain, of which he had been curator since r862. He was also professor at the École de Louvre of national archæology, and his fame as an archæologist was world-wide.

THE great dam on the Nile at Assuan is to be inaugurated by the Duke and Duchess of Connaught as we go to press with this number. Sir Benjamin Baker, K.C.M.G., has been appointed to be a Knight Commander of the Order of the Bath, in recognition of his services in connection with the construction of the Nile reservoir. Other honours conferred in connection with the work are :-To be G.C.M.G., Sir William Edmund (jarstin, K.C.M.G., Under-Secretary of State for Public Works in Egypt. To be K.C..M.G., Major R. H. Brown, R.E., C.M.G., 